\title{
36
}

\section{Hausa and the Chadic Languages}

\author{
Paul Newman
}

\section{Chadic}

The Chadic language family, which is a constituent part of the Afroasiatic phylum, contains some 140 languages spoken in the sub-Saharan region west, south and east of Lake Chad. The exact number of languages is not known since new languages continue to be discovered while other supposedly independent languages tum out to be mere dialects or tenninological variants. The most important and best-known Chadic language is Hausa. Other Chadic languages are considerably smaller, ranging from a quarter of a million speakers to less than a thousand. Most of the languages at the lower end of the spectrum are now seriously endangered.

The languages in the family fall into three major branches plus a fourth independent branch. The West Chadic Branch, which includes Hausa, contains about 60 languages divided into seven groups. All of these languages are spoken in northern Nigeria. The Biu-Mandara (or Central) Branch contains over 45 languages, assigned to eleven groups, extending from the Gongola and Benue river basins in Nigeria to the Mandara Mountains in Cameroon. The East Chadic Branch contains about 25 languages belonging to six groups. These are scattered across central Chad in a southwest-northeast direction from the Cameroon border to the Sudan border. The Masa Branch consists of a single group of some half a dozen closely related languages spoken between the most southeasterly Biu-Mandara languages and the most southwesterly East Chadic languages. A comprehensive list of Chadic languages organised by branch and group is given in' Table 36.1. Within each group, the languages are listed alphabetically rather than according to closeness of relationship. Names in parentheses indicate alternative nomenclature or dialect variants.

Although the relationship of Chadic (originally only Hausa) to other Afroasiatic languages was proposed some 150 years ago, it has gained general acceptance only within the last quarter of a century. The inclusion of Chadic within Afroasiatic is based on the presence of features such as the following: (a) a formative $t$ indicating feminine, diminutive and singulative; (b) an $n / t / n$ 'masculine/feminine/plural' agreement marking pattern in the deictic system; (c) an $m$ - prefix forming agential, instrumental and locational nouns; 
Table 36.1 The Chadic Language Famly (Inventory and Classification)

West Charlie Branch

1 Hausa group: Gwandara, Hausa.

2 Bole group: Bele, Bole (Bolanci), Deno (Kubi), Galambu, Gera, Gerurna, Kanalcuru (Dera), Karekare, Kirfi, Kupto, Kwami, Maha, Ngamo, Pero, Piya (Wurkum), Tangale.

3 Angas group: Angas, Chip, Gerka (Yiwom), Goemai (Ankwe), Koenoem, Kofyar, Montol (Teel), Pyapun, Sura (Mupun), Tai.

4 Ron group: Fyer, Karfa, Kulere, Mundat, Ron (Bokkos, Daffo), Sha, Shagawu, Tambas.

5 Bade group: Bade, Duwai, Ngizim.

6 Warji group: Diri, Jimhin, Kariya, Mburku, Miya, Pa'a, Tsagu, Warji.

7 Zaar group: Barawa, Boghom, Dass, Dott, Geji, Guruntum, Guus (Sigidi), Jirni, Ju, Mangas, Polchi, Zaar (Sayanci), Zari (Zakshi), Zeem.

IT Biu Mandara Branch

I Tera group: Ga'anda, Hona, Jara, Tera (Pidlimdi, Yamaltu).

2 Bura group: Bura (Pabir), Chihak, Kilba, Margi, Putai (West Margi).

3 Higi group: Bana, Higi, Kapsiki.

4 Mandara group: Dghwede, Glavda, Guduf, Gvoko, Hdi (Hide), Lamang (Hitkala), Mandara (Wandala), Podoko.

5 Matakarn group: Gisiga, Huna-Varne, Mada, Matakam (Mafa), Mofu-Duvangar, Mofu-Gudur, Moloko, Muktele, Muyang, Uldeme, Zulgo.

6 Sukur group: Sukur.

7 Daba group: Buwal, Daba (Kola, Musgoi), Gawar, Hina.

8 Bata group: Bacharna, Bata, Gude, Ni.angi (Jeng).

9 Kotoko group: Buduma (Yedina), Kotoko, Logone.

10 Musgu group: Mbara, Musgu (Munjuk, Mulwi).

11 Gidar group: Gidar.

III East Chadic Branch

1 Somrai group: Gadang. Miltu, Mod, Ndarn, Somrai (Sibine), Tumak.

2 Nancere group: Gabri (Tobanga), Kabalai, Lele, Nancere.

3 Kera group: Kera, Kwang (Modgel).

4 Dangla group: Bidiyo, Birgit, Dangla (Dangaleat), Jegu, Kujarge, Mawa, Migarna

(Jonkor of Abu Telfan), Mogum, Mubi, Toram.

5 Mokulu group: Mokulu (Jonkor of Guera).

6 Sokoro group: Barain, Saba, Sokoro.

IV Masa Branch

1 Masa group: Marba, Masa, Mesme, Musey, Zime (Lame, Peve).

(d) formation of noun plurals inter a/ia by a suffix $-n$ and an infix - $a$-; (e) a common pronominal paradigm; (f) a pattern of suppletive imperatives with the verbs 'come' and 'go'; (g) shared gender specification of individual words; and (h) cognate items for basic vocabulary including 'body', 'die', 'drink', 'fire', 'know', 'name', 'water' and 'what'. Some scholars have suggested that Chadic is the most distant Afroasiatic family member (apart from Omotic), while others have suggested an especially close tie with Berber; but, so far, such proposals have been made essentially on impressionistic grounds.

Charlie languages belonging to separate groups appear quite different from one another, reflecting the great time depth within the family; nevertheless, they invariably can be identified as Charlie because of shared core features. In describing common Chadic characteristics, it should be kept in mind that these features are neither present 
nor found identically in all Chadic languages, nor are they necessarily reconstructable for Proto..Chadic.

All Chadic languages, as far as we are aware, are tonal. One finds simple two-tone systems (Margi), two tones plus downstep (Kanakuru), three tones (Tera) and three tones plus downstep (Ga'anda). Vowel systems range from two vowels, // and /a/ (as in Mandara), to seven vowels, /i e E a :> o u/ plus distinctive vowel length (as in Dangla). Cross-height vowel harmony of the common West African type is rare in Chadic but it does occur, inexplicably, in Tangale. A typical Chadic feature is to have a different number of vowel contrasts depending on the position within a word. Old Hausa, for example, had two vowels initially, three plus vowel length medially and five vowels without a length contrast finally. Most Chadic languages have a set of glottalised consonants (usually laryngealised or implosive) in addition to the voiced and voiceless ones. Goemai and a few other languages in the same subgroup have the unusual feature of contrasting ejective and implosive consonants at the same position of articulation, e.g. IrJI vs $/ 6 /$, If $/$ vs $/<f l$. While the glottal Stop $n t$ occurs as a phoneme in many languages, it invariably represents a secondary historical development: it is not reconstructable for Proto-Chadic. Finally, one should note the widespread presence of lateral fricatives (/ii and $f M$ throughout the family. They have been lost in the East Chadic Branch and in some sub-branches of West Chadic, but elsewhere they are extremely common.

In the realm of morphosyntax, Chadic languages typically have pluractional verb stems (formerly called 'intensives') that indicate the plurality of action, i.e. action done a number of times, by a number of subjects or affecting a number of objects. These pluractional stems are formed by reduplication, gemination and/or by insertion of an internal -a-, e.g. Ga'anda 6:Jl- 'kill', \&6al- 'kill many'. In a few languages, the use of pluractional stems has become grammaticalised, resulting in ergative-type number agreement, i.e. obligatory use of pluractional stems with plural subjects of intransitive verbs and plural objects of transitive verbs, e.g. Kanakuru na oope gaminii 'I tied the rams'; (oope<•ooppe); gaminii 'WUdOpo-'WU 'the rams are tied'; cf. 'WU dOwe gamii 'they tied the ram'; gamii a oowe-ni 'the ram is tied'. The Kanakuru examples illustrate another distinctive Chadic feature (but with scattered distribution), namely the so-called ICP ('Intransitive Copy Pronoun') construction. In various languages, all or some intransitive verbs optionally or obligatorily suffix a pronoun that copies the person and number of the subject. In Ngizim, for example, the use of the ICP is optional and adds an extra meaning of completeness to the verb phrase. In Kanakuru. on the other hand, the use of the ICP is obligatory with all intransitive verbs, but limited to certain tenses, e.g. kilpdri>-IW 'you went out', not *kQporo; kilei a taae-ni the pot broke', cf a taae kilei 'he broke the pot'. Note that ICPs in Chadic are different from reflexive pronouns in both form and function, the latter typically consisting of the noun for 'head' or 'body' plus a possessive pronoun and occurring syntactically as the direct object of a transitive verb.

Verbs in Chadic typically employ derivational extensions indicating action in, towards, down, up, away or totally or partially done. Sometimes the extensions are more grammatical in nature, indicating benefactive, perfective or transitivisation. In some languages, such as Tera, the extensions are separate particles; in some, such as Margi, they are semi-bound suffixes; in others, such as Hausa, they have become fused into the verb stem.

Grammatical gender in Chadic is a fairly straightforward phenomenon that goes back to Proto-Chadic (and more distantly to Proto-Afroasiatic as well). The many Chadic 
languages that do not now have gender have all lost it, this having happened independently a number of times at the level of language, group, subgroup and cluster. Languages that have gender invariably distinguish two genders (masculine and feminine) and in the singular only. Gender distinctions are absent in the plural. In the pronominal system, gender is typically marked in the second as well as the third person.

Regarding word order, Chadic languages are prepositional and place the possessor following the thing possessed. Many languages distinguish inalienable possession fonned by simple juxtaposition from alienable possession, which makes use of a connecting particle, e.g. Tera Jpmndro 'your ear' vs kaskar 6a-ro 'your sword'. Attributive adjectives usually follow the noun being modified and numerals invariably follow the noun. The most common order for verbal sentences is $\mathrm{S}$ (ubject\}-V(erb -O (bject), this almost certainly being the basic order in Proto-Chadic. SOV in Chadic is unattested. VSO does occur in a small number of Biu-Mandara languages spoken in the Nigerian-Cameroon border region; evidence suggests that this represents an areal innovation rather than being an archaic feature of the family.

\section{Hausa}

\subsection{Introduction}

Hausa is spoken as a mother tongue by some 25 to 30 million people representing the original Hausa population as well as by people of Fulani ancestry who established political control over Hausaland at the beginning of the nineteenth century. It is the majority language of much of northern Nigeria and of the Republic of Niger. Hausa speakers are also found in Togo and Ghana and in small colonies of settlers and traders in large towns in West Africa. In addition, there is a Hausa-speaking community in the Blue Nile area of Sudan, dating from the British take-over of northern Nigeria at the beginning of the twentieth century.

Hausa is also widely spoken as a second (or third) language in Nigeria and Niger, functioning as a lingua franca for commercial, infonnational and governmental purposes. Hausa is one of the three indigenous national languages recognised in the Nigerian constitution. Whereas secondary and higher education in northern Nigeria are generally in English, Hausa is commonly the de facto language of instruction in the primary schools. Hausa is now offered as a major degree subject in a number of Nigerian universities. There are many Hausa language newspapers and magazines, a thriving literature and extensive use of the language in radio and television. Hausa language broadcasting is provided not only within Nigeria and Niger, but also by international transmissions from Britain, the USA, Germany, Russia and China. With approximately 40 or so million first- and second-language speakers, Hausa ranks with Swahili as one of the two most important languages in sub-Saharan Africa.

Within the Chadic family, Hausa essentially constitutes a group by itself. Gwandara, the only other member of the group, is a historically relatively recent creolised offshoot of Hausa. The West Chadic groups most closely related to it are the Bole group and the Angas group. What sets Hausa apart from its sister (or cousin) languages is the richness of its vocabulary, due in large part to the enonnous number of loanwords from other languages. Tuareg and Kanuri, for example, have contributed significantly to Hausa vocabulary; but the major influence by far has been Arabic (sometimes by way of one 
or the other of the just-mentioned languages). In certain semantic spheres, e.g. religi<4 government, law, warfare, horsemanship, literature and mathematics, Hausa is literaJI swamped with words of Arabic origin. Inthe past century, Hausa has absorbed a massive new wave of loanwords from English (in Nigeria) and French (in Niger). This influence continues unabated.

Compared with other large African languages, dialect variation within Hausa is relatively modest. Nevertheless, on the basis of systematic differences in pronunci4 and grammar, it is possible to distinguish a Western dialect (or dialects) (e.g. Sokot\&S and Gobir) fium an Eastern dialect (Kano and z.aria), with Katsina occupying an interlo mediate position. The dialect described here, which has become established as 'standaitl Hausa', is that of greater Kano, the largest and most important Hausa city.

\subsection{Phonology}

The phonemes of the standard dialect of Hausa are presented in Table 36.2. There are 32 consonants, 12 vowels (five basic vowels with corresponding long and short varian11 plus two diphthongs) and three tones (two basic tones plus a compound tone). The richness in the consonantal inventory is due to the presence of: (a) a set of glottalisecl consonants alongside the voiced and voiceless ones, e.g. $/<f /$ vs $/ \mathrm{t} /$ and $/ d i$, and (b) palatalised and labialised consonants alongside simple ones, e.g. $/ \mathrm{ky} /$ and $/ \mathrm{kw} / \mathrm{vs} / \mathrm{kl}$. In Table 36.2 (and in all examples given), the symbols $c$ andj represent the affricates [ $\mathrm{fl}$ and $[\mathrm{cB}]$ respectively. The 'hooked' letters 6 and arepresent laryngealised stops; '. $Y$ is a laryngealised semi-vowel, historically derived from ${ }^{*} £ 61$, whereas $K, f y, K w$ and $t s$ are

Table 36.2 Phonemes of Hausa

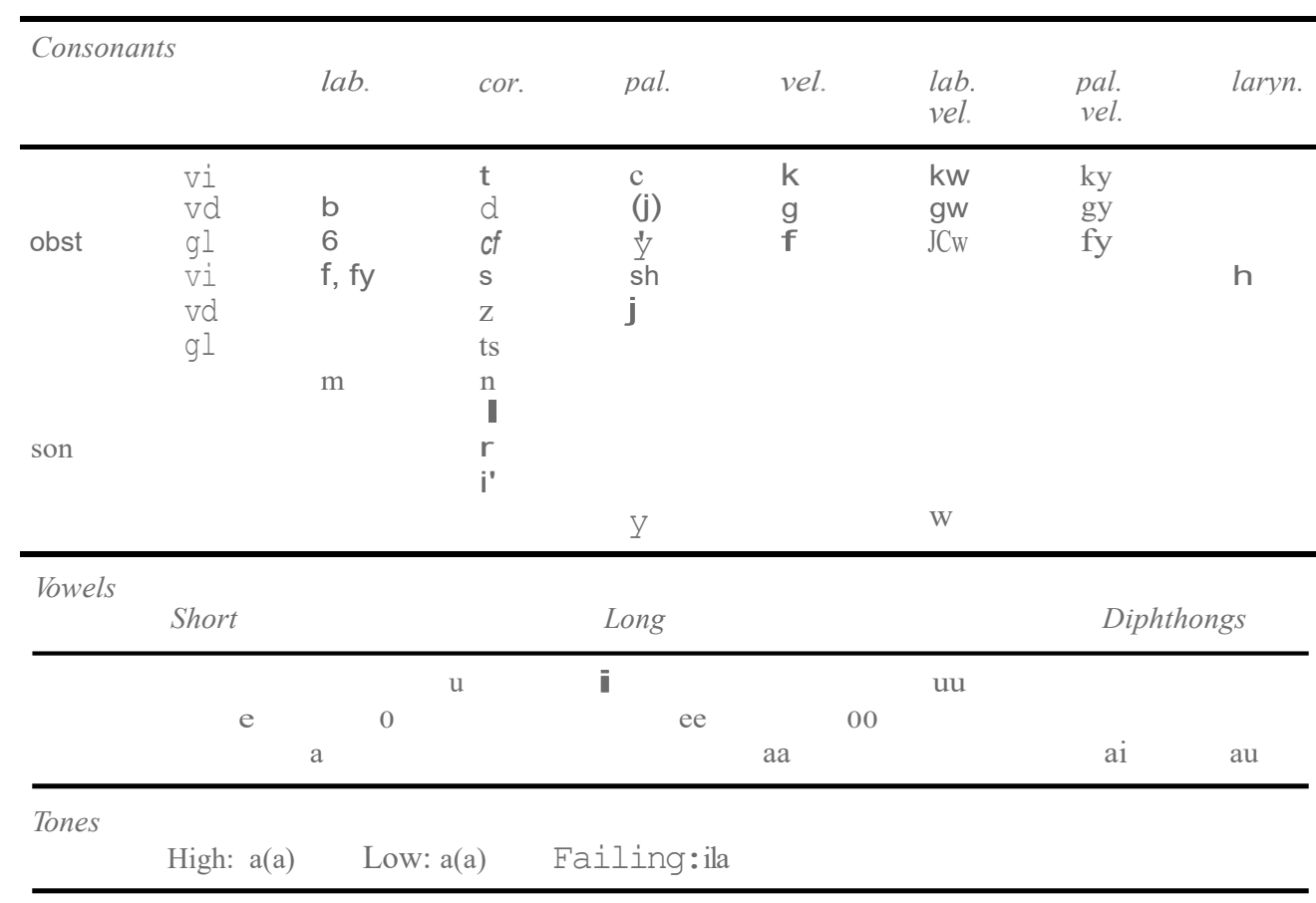


cdectives. Th $\leftrightharpoons$ pronunciatin or. e consont written

th digraph $t s$ is [s'] (an gective sibilant), but there is mdlVldual and dialectal vanation, mcludmg [tJ'] and [ts']. The apostrophe /'I by itself is used to represent the glottal stop phoneme.

The /f/ phoneme is variably pronounced as $[\mathrm{f}],[<\mid>]$ or $(\mathrm{p}]$. Structurally, it fills the $p$ slot in the voiceless stop series. Before back vowels it is usually pronounced (and written) as /hi, e.g.jeefi 'throw', $c f$.jeehi $>_{O}$ 'throw in this direction'. The nasals $/ \mathrm{n} /$ and /rn/ are generally pronounced [IJ] in final position, e.g. /nfin/ 'here' [nfu.J]; /maalamt •teaeher' [maalam] or [maall $\backslash 1)]$. When immediately followed by a consonant, whether in the same word or across a word boundary, In/ (always) and $/ \mathrm{ml}$ (usually) assimilate to the position of the abutting consonant, eg. sun bi 'they followed' [sfun bi]; fahimtaa 'understand' [fabintaa]. Hausa has two distinct rhotics: a retroflex flap [t] and an apical tap or roll [r]. The two sounds are not distinguished in Hausa orthography. In scholarly linguistic works, the tap/roll is sometimes indicated $\mathrm{Ir} /$ or $/ R I$ or more often If/, to set it apart from the flap, which is written as /r/, e.g. raanaa 'sun', farktia 'paramour', cf. Piibaa 'protit',farkda 'wake up'. All Hausa consonants can occur as geminates as well as singly, e.g. cillaa 'shoot far', cf. cilaa 'pigeon'; diddigee 'heel' (< *digdigee), cf. plural digaadigai. Although from a technical perspective the geminates need to be analysed at some level as unitary segments, for most purposes they can be viewed simply as two identical abutting consonants, i.e. cillaa $=/ \mathrm{C}_{1} \mathrm{iC}_{2} \cdot \mathrm{C}_{3} \mathrm{~W}$.

The five long vowels in Hausa have typical IPA 'Italian' values. In non-final position, short lii, /al and $/ \mathrm{u} /$ are more lax and centralised. (Non-final short /e/ and /o/ have a marginal status in Hausa.) The contrast between long and short vowels is extremely important, both lexically and grammatically, e.g. Gaacee 'spoil', 6acee 'vanish';ji imaa 'tanning', ji maa 'pass time'; 'idoo 'eye', 'ido 'in the eye'; shaafee 'wiping', shaafe 'wiped' (past participle); tao 'she (completive)', ta 'she (preterit)'. The two diphthongs /ail and /au/ are best treated as complex vocalic nuclei, although many Hausaists prefer to analyse them as /ay/ and /aw/. The former is generally pronounced [ei] or even [ee], tending to merge with long /ee/; the latter varies in the [ao], [au], [ou] range, normally remaining distinct from long loo/.

Hausa has two basic tones: high, indicated $a(a)$, and low, indicated $a(a)$, e.g. gi>oraa 'bamboo', gooraa 'large gourd', maataa 'wife', maattia 'wives', kiraa 'call', kiraa 'calling', ta 'she (preterit)', ta 'she (subjunctive)'. A sequence of high plus low on a single syllable is realised as a falling tone, e.g.yaaraa 'children' (=/yilrial), mantaa 'forget' $(=/ \mathrm{mmit} 8 \mathrm{a} /)$. In many cases falling tones are the result of the grounding of a low tone belonging to a following morpheme, e.g. kOomoowaa 'returning' (=/k6om60waat) comes from kOomoo 'return' plus '-waa '-ing'. Falling tones, being tone sequences, only occur on heavy syllables, both CVV and eVe types. There is no rising tone corresponding to the fall. A low-high sequence on a single syllable is usually simplified to high, e.g. tausai 'pity' < *tausai (<tausayii); diiukda 'take' < *dilukda.

Hausa has three syllable types only: CV, which is light, and CVV (where VV can be a long vowel or a diphthong) and eve, which are heavy, e.g. suu.ntin.sa 'his name', kUjee.rar 'the chair', 'a.kwaa.ti 'box'. While consonants may abut across syllable boundaries, e.g. kOs.kda 'tick', there are no consonant clusters within a syllable. Syllable weight is an extremely important variable in the language: it is crucial for metrical and tonal rules and plays a major role in morphological processes. Given the restriction on syllable types, it follows that long vowels cannot occur in closed syllables. Such overheavy syllables, which are created in intennediate structure by morphological formations, are eliminated phonologically by automatic reduction of the nucleus, e.g. 
'aikii-n-sa -+ 'aikinsa 'his work' (lit. 'work-of-his'); mai-n gyQOOa -+ man gyadi:la 'groundnut oil'; *buucJ:.bUudee -+ bUbbuudee 'open many/often'; *faad'mini (contracted from faadaa mini) far mini 'attack me'.

\subsubsection{Orthography}

Hausa makes use of two writing systems, one, called bOoki>o, based on the Latin alphabet, the other, called 'ajami, based on the Arabic writing system. The Latin system was introduce $<$ ! by the British in Nigeria at the beginning of the twentieth century. This western orthography is used in the schools, in the major Hausa newspapers and in most other modern books and magazines. The system as now established makes use of the symbols in Table 36.2 with the following differences. Glottal stop (') is not written in wordinitial position. The phonemic distinction between the two Rs is ignored. Vowel length is not marked, nor is tone. An earlier attempt in Niger to mark vowel length by double letters was subsequently dropped, so that there is now a more or less unifonn orthography in the fonner French and fonner British countries. On the whole the writing system is phonemic (even subphonemic in places) although some assimilatory changes are not noted in order to preserve morphological regularity. Thus one writes sun bi 'they followed', not sum bi, and ribar nan 'that profit', not riban nan.

The writing of Hausa in Arabic script ('ajami) dates from the beginning of the nineteenth century, possibly a little earlier. Although government policy since the beginning of this century has been to replace 'ajami by b6olc0o, it is still widely known and used. The 'ajamiscript is learned in Koranic schools and is preferred over b6ok0o not only by religious writers but also by many of the more popular traditional poets. After a long period of purposeful neglect, 'ajami has begun to be used again in newspapers.

\subsubsection{Morphophonemic processes}

Hausa exhibits a tremendous amount of morphophonemic alternation, sometimes through active phonological rules, sometimes reflecting earlier historical changes. Depending on the phonological environment, the 'altered' segment may appear either in the basic fonn of a word or in a derived fonn. I shall here describe only some of the more general processes producing alternations.

(a) When followed by a front vowel, $t, s$ and $z$ palatalise to $c$, $s h$ andj, respectively, e.g. saataa 'stealing', saace 'stolen'; dukUshii 'colt', pl. dukUsai; mijii 'husband/ male" pl. mazaa or mazaajee. The palatalisation rule does not apply automatically to recent loanwords, e.g. tiitii 'street' (from English via Yoruba); ltifazii 'pronunciation' (from Arabic). The voiced stop $d$ also changes to $j$ (with resulting neutralisation of the $d / z$ contrast), but this change is not as regular as with the other alveolars, even in native words and constructions, e.g. gidaa 'house', pl. gidaajee; cf. klldaa 'crocodile', pl. kild6odii; kUdu 'south', bakUdee 'southerner' . Palatalisation also affects velars, but it is not reflected in the orthography except in the case of the $w, Y$ alternation, e.g. Garaawoo 'thief', pl. Garaayii.

(b) As indicated above, long vowels are automatically shortened in closed syllables. At nonnal speech tempos, resultant short $e$ and $o$ merge with short $a$, e.g. daree-n-nan -+dartinnan 'this night'; kllnoo-ndi -+ kllnancii 'Kano dialect'. The original quality of the vowel often shows up as palatalisation or labialisation of 
the preceding consonant, e.g. dashee-n-su --. dashtinsu 'their seedlings' (cf. dasaa 'transplant seedlings'); geeffaa --. gyaffaa 'sides' (pl. of geefee); f6onfoonaa --. fwan-foonaa 'keep on burning'.

(c) In syllable-final position, obstruents historically underwent a series of lenition changes known as Klingenheben's Law (see Newman 2004). Velar and bilabial stops (the latter in Eastern dialects only and even there in incomplete fashion) weakened to $u$ (with subsequent simplification of the diphthong $i u$ to $u u$ ), e.g. taiakil 'commoner', talaucii 'poverty'; buuzuи 'Tuareg serf', pl. bUgaajee; juujii (<*jiujiz) 'rubbish heap', pl.jibaajee. (Note that some of these synchronically irregular plurals are nowadays being replaced by more transparent forms such as bUuzaayee andjuujaayee.) The bilabial change also applied to $m$, but only when the abutting consonant was an alveolar sonorant, e.g. 'auree 'marriage', cf. 'cimciryaa 'bride'.

(d) In syllable-final position, alveolar stops change to $r$, e.g. fadakar 'wake up, enlighten', farkila 'wake up' (intransitive); 6ata 'spoil', 6afncia 'destruction'; $k a d a=k d r$ 'prohibitive marker'. This change both took place at a historically earlier period and is still operative synchronically. The rhotacism also applies to alveolar sibilants but only in the context of reduplication, e.g. mcizci 'quickly', mazamazci = mai'maza 'very quickly'; $t$ Umus-musaa - tUmurmusaa 'wallow in the dirt'.

(e) In reduplicative constructions, syllable final velars and labials form geminates with the following consonant rather than undergoing Klingenheben's Law, e.g. zaaf-zaafaa - zazzaafqa 'very hot' (not *zauzaafaa), sai-saKiza - sassaKiza 'carve'. Syllable-final alveolar obstruents also undergo gemination but usually as an alternative to rhotacism, e.g. kli<f-kilcf!ia --. k!ikkildaa or karkilcf!ia 'keep beating'.

\subsection{Morphology}

\subsubsection{Pronominal System}

The pronominal system distinguishes five categories in the singular (1, 2-masculinc, 2-feminine, 3-masculine, 3-feminine) and four in the plural (1-pl., 2-pl., 3-pl. and the so-called '4-pl', which only occurs as an impersonal weak subject pronoun). There is no gender distinction in the plural. Variant pronoun sets, differing primarily in tone and vowel length, are shown in Table 36.3. Their use is determined by surface syntactic position and function.

The independent pronouns (set a) are used as absolute pronouns, e.g. nii nee 'it's me'; as subjects of equational sentences, e.g. kai yciaroo nee 'you're a boy'; as objects of the particle $d a$ 'and/with', e.g. sun zoo da 'itci 'they came with her', nii da kee mun yafdci 'I and you (we) agree'; as direct objects when not immediately following the verb, e.g. kilaw6o mini shii 'bring me it'; and as fronted, focused forms, e.g. Me cee mukil ganii 'you (fem.) were the one we saw', suu nee sukil tafi 'they were the ones who went'. The object pronouns (set b) are used as direct objects of verb 'grades' 1 and 4 (see Section 2.3.2 below for a discussion of the grade system), e.g. naa karantaa SU 'I read them'. Pronouns of the same form are also used as subjects of the verboid zaa 'be going', e.g. zaa ta kilasuwaa 'she's going to market', and of the negative particle baa, e.g. baa shi da tciawiil 'he doesn't have a towel' (lit. 'there-is-not him with towel'). 
The object clitics (Set c) are used as direct objects of other verb grades, e.g. ntia tambayee $s u$ 'I asked them', and as object of the common word 'akwai 'there is/are', e.g. 'akwai su dtl yawaa 'there are many of them' (lit. 'there-are them with many'). The forms in set $\mathrm{d}$ are bound to the indirect object marker $m a$ - (with an assimilatory vowel), e.g. masa, mini, mukU 'to him, to me, to you (pl.)'. The forms in set e are used with the gender-sensitive linkers $n(a)$ (masculine and plural) and $t a / r$ (feminine), e.g. naakd 'yours' (masculine or plural referent), littaafinkd 'your book', taasu 'theirs' (feminine referent), m0otarsu 'their car'. The first person is slightly irregular, e.g. naawwtaawa 'mine', littaafiinaa $(-\mathrm{naa}=\mathrm{na}+a)$ 'my book', mootaataa $(-\mathrm{ta} . \mathrm{a}=$ ta $+a)$ 'my car'.

Hausa TAMs, which reflect tense, aspect, mood and aktionsart, or a combination thereof, are indicated by a marlcer attached in preverbal position to a weak subject pronowi. Some of the markers are clearly segmentable whereas others consist only of tone or vowel length modifications of the basic pronoun. In the case of the subjunctive, the marker is 0 . Thus it has become the convention in Hausa studies to treat the pronoun plus marker as a fused tense/aspect pronoun, also referred to as a person/aspect complex; see Table 36.4. Negative tense/aspect pronouns, which differ from the corresponding affirmative ones, are listed separately. Apart from the continuous, which uses a single negative marker baa, and the subjunctive, which uses a prohibitive particle kadtl, verbal sentences arenegated by means of a discontinuous morpheme $b a(a)$... bti. The meanings of the tenses are roughly deducible from their labels and will not be

Table 36.3 Independent, Object and Possessive Pronouns

\begin{tabular}{|c|c|c|c|c|c|}
\hline & 11 & $b$ & $c$ & II & e \\
\hline & nli & $\mathrm{nf}$ & $-n l$ & -ni & $-(w) A$ \\
\hline $2 \mathrm{~m}$. & kai & $\mathrm{ka}$ & $-k A$ & $-\mathrm{ka}$ & $-\mathrm{kA}$ \\
\hline $2 \mathrm{f}$. & kee & $\mathrm{kf}$ & -Id & $-I d$ & $-I d$ \\
\hline $3 \mathrm{~m}$. & shii & sh! & -shi & -s8/shi & s8/shi \\
\hline $3 \mathrm{f}$. & 'itA & ta & -ta & -ta & - ta \\
\hline I pl. & muu & $\mathrm{mu}$ & $-m u$ & $-M$ & $-m u$ \\
\hline $2 \mathrm{pl}$. & $\mathrm{kUu}$ & $\mathrm{lcU}$ & $-\mathrm{kU}$ & $-k U$ & $-k U$ \\
\hline $3 \mathrm{pl}$. & suu & $\mathrm{SU}$ & -SU. & SU. & SU. \\
\hline
\end{tabular}

Note: $\mathrm{a}=$ independent: $\mathrm{b}=$ object pronoun; $=$ object clitic; $\mathrm{d}=$ indirect object; $\mathrm{e}=$ possessive

Table 36 Tense/Aspect Pronouns

\begin{tabular}{|c|c|c|c|c|c|c|c|c|c|c|}
\hline & a & $b$ & c & $d$ & $e$ & 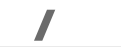 & $g$ & $h$ & & $j$ \\
\hline & naa & na & baa.•.ba & $\operatorname{zin}$ & nh & naican & 'in & 'fuula & n8ke(e) & Mana.a \\
\hline $2 \mathrm{~m}$. & kaa & ki & bill...ba & zaalc.a & kia & illan & $\mathrm{kA}$ & kan8a & ille(e) & bAak\&a \\
\hline $2 f$. & kfn & kfkA & bllki...ba & zc!.ak1 & kyaa & klkan & $\mathrm{kf}$ & $\mathrm{k} \ln 8 \mathrm{a}$ & .ldke(e) & bc!.akyaa \\
\hline $3 \mathrm{~m}$. & y8a & ya & b\&. $\bullet$ ba & zfil & yia & ya.Ican & ya & y\&naa & ya.ke(e) & bBayaa \\
\hline 3f. & t8a & $\mathrm{tA}$ & batA...ba & 7.Aata & tia & tAkAn & ta & tAnaa & ta.Ice(e) & baataa \\
\hline $\mathrm{Ip}$ & miin & mUka & bamu...ba & 7.Aamu & mia & mfilcan & $\mathrm{mu}$ & miinaa & mUke(e) & baamaa \\
\hline $2 \mathrm{pl}$. & $\mathrm{kUn}$ & kUlcA & bllkU ...ba & 7.8akU & kwaa & kUkan & $\mathrm{kU}$ & IcUnaa & klike(e) & b\&akwaa \\
\hline $3 \mathrm{pl}$. & SUn & sUka & bAsu ...ba & zaasU & s8a & sUkan & SU & SUnaa & sUke(e) & baasaa \\
\hline $4 \mathrm{pl}$. & 'An & 'ill & ba'a...bB & zaa'a & ea & aari & a & 'anaa & 'ake(e) & baa'aa \\
\hline
\end{tabular}

Notes: a "' completive; $b=$ preterit; $c=$ neg completive; $d=$ future; $e=$ potential future; $f=$ habitual; $\mathrm{g}=$ subjunctive; $\mathrm{h}=$ continuous; $\mathrm{i}=$ rel continuous; $\mathrm{j}$ = neg continuous. 
discussed. A syntactic alternation involving the completive and the preterit and the two continuous TAMs is described in Section 2.4.

Except for the imperative, which is marked by low-high tone (sometimes plus a final vowel change), the verb itself is not conjugated, tense, person and number being shown by the tenselaspect pronoun, e.g.naa zaunaa 'I sat'; Mnaa zaunaa $\mathrm{M}$ 'I don't intend to sit';zaamu zOunaa'wewillsit'; mu Zaunaa 'let'ssit'; takan Ktiamaa sU'she catches them'; tanaa kflamaa SU 'she is catching them'; cf. zaunaa 'sit!';kaamaa SU 'catch them!'

\subsubsection{Verbal Morphology}

Verbal morphology reflects the verb's 'grade' and its syntactic environment. The morphological distinctiveness in each category is defined in terms of the verb's final vowel (or - VC) and overall tone. The pattern for each grade, indicated for two- and threesyllable verbs, is presented in Table 36.5 .

Grade 1 contains basic transitive verbs with underlying final $-a$ as well as derived 'applicatives' (often required with indirect objects). Like the efferential (grade 5), grade 1 applicatives serve to transitivise intransitive verbs, e.g. sun haKil raamii 'they dug a hole' (basic); kafadlza Mana gtiskiyaa 'you should tell us the truth' (applicative); tanaa cfka tUuluu 'she is filling the pot' (applicative). Grade 2 contains basic transitive verbs with underlying final $-i$ as well as derived verbs with a partitive sense, e.g. baka fadi gtiskiyaa bQ 'you didn't tell the truth' (basic); mu yanki naamila 'let's cut off some meat' (partitive). Grade 3 is an exclusively intransitive grade containing verbs with underlying final $-a$, e.g. fita 'go out'; cikfl 'be filled'. Grade 4 ('totality') indicates an action totally done or affecting all the objects, e.g. rowaa yaa zubee 'the water all spilled out'; zaamu saye shinkflafaa 'we will buy up the rice'. When used with an indirect object, grade 4 often has a malefactive or deprivative sense. With many verbs, especially when used intransitively, Grade 4 is becoming a basic, semantically neutral form. Grade 5 ('efferential'), traditionally called 'causative' in early grammars, indicates action away from the speaker. It also serves to transitivise inherently intransitive verbs, e.g. yaa 'aurarda yaa ttisa 'he married off his daughter'; taafi tilr 'she took (it) out'. Note that Grade 5, whose suffix -ar derives historically from •-as, is the only grade that ends in a consonant. Grade 6 ('ventive') indicates movement in the direction of or for the benefit of the speaker, e.g. kUn sayoo 'ashtlanaa? 'did you (pl.) buy (and bring) matches?'; zaatil fit6o 'she will come out'. Grade 7 ('sustentative') indicates an agentless passive (or sometimes middle voice), action well done or the potentiality of

Table 38.5 The Hausa Grade System

\begin{tabular}{|c|c|c|c|c|c|c|}
\hline & Form A & & Form B & & Form C & \\
\hline $\begin{array}{l}\text { Grade } 1 \\
\text { Grade } 2\end{array}$ & $\begin{array}{l}\text {-aa } \\
\text {-aa }\end{array}$ & $\begin{array}{l}\mathrm{H} \mathrm{L}(\mathrm{H}) \\
\mathrm{L} \text { H }(\mathrm{L})\end{array}$ & $\begin{array}{l}-\mathrm{aa} \\
-\mathrm{ee}\end{array}$ & $\begin{array}{l}\mathrm{HL}(\mathrm{H}) \\
(\mathrm{L}) \mathrm{L} \mathrm{H}\end{array}$ & $\begin{array}{l}-\mathrm{a} \\
-\mathrm{i}\end{array}$ & $\begin{array}{l}\mathrm{H} \text { L (L) } \\
\text { (L) L H }\end{array}$ \\
\hline Grade 3 & $-\mathrm{a}$ & L H (L) & & & & \\
\hline Grade 4 & -ee & H L (H) & -ee & H L (H) & C.e & $\begin{array}{l}\text { H L (L) } \\
\text { H L (H) }\end{array}$ \\
\hline Grade 5 & -ai' & $\mathrm{H} \mathrm{H}(\mathrm{H})$ & -shee & $\mathrm{H} \mathrm{H}(\mathrm{H})$ & & \\
\hline Grade 6 & -00 & $\mathrm{H} \mathrm{H}(\mathrm{H})$ & -00 & $\mathrm{H} \mathrm{H}(\mathrm{H})$ & 00 & H H (H) \\
\hline Gnde 7 & $-u$ & (L) $\mathrm{L} \mathrm{H}$ & & & & \\
\hline
\end{tabular}


sustaining action, e.g. naaniaa yaa gasu 'the meat has been roasted'; 'ag6og6 baayao gyaarowaa 'the watch is not repairable'. Hausa has a small number of high-frequen.,I monosyllabic verbs, e.g. $b i$ 'follow', $c i$ 'eat',jaa 'pull', shaa 'drink', s6o 'want'. These do not fit into grades 1, 2 or 3, but they do appear in the other grades (with slightly variant forms), e.g. yaa shfznye rowaa 'he drank up the water' (gr. 4); mululn ciishee SU 'we feed them' (gr. 5); jaaw6o nan 'pull (it) here' (gr. 6); hanyaa taa biyU 'the road will be passable' (gr. 7). Most scholars now incorporate these verbs into the grade system as grade 0 .

Cross-cutting the grades, verbs have three syntactically determined forms (omitting the pre-indirect object position, which poses special problems). Form B is used when the verb is immediately followed by a personal pronoun direct object. Form $\mathrm{C}$ is used when the verb is followed by any other direct object. Form A is used elsewhere, e.g.

taa taimaki Muusaa taa taimakee shi

Muusaa nee ta taimakaa mun kizfanta ja fiidaa mun kizfantaa ta waccee kU/c: a kizrantaa?

\author{
'she helped Musa' \\ 'she helped him' \\ 'it was Musa she helped' \\ 'we read the newspaper' \\ 'we read it' \\ 'which did you (pl.) read?'
}

(gr. 2, C)
(gr. 2, B)
(gr. 2, A)
(gr. 1, C)
(gr. 1, B)
(gr. 1, A)

Grade 5 ('efferential') verbs do not have a $\mathrm{C}$ form since its semantic objects are expressed as oblique objects introduced by the particle $d a$ (the same as or homophonous with the preposition $d a$ 'with'), e.g. yanaa k6oyar da Hausa 'he is teaching Hausa'. With object pronouns, one may use either the B form plus a pronominal clitic or the A form with the oblique object, e.g. yaa ciishee ta = yaa ciyaf da 'ita 'he fed her'. Some verbs allow a short form variant without the suffix -ar before $d a$, e.g. taa $z u b$ da rowaa = ttia zubdr da rowaa 'she poured out the water'.

\subsubsection{Verbal Nouns}

While verbs as such are not inflected for tense, in the continuous tenses they are subject to replacement by verbal-nominal forms, of which there are three general classes: (1) weak verbal nouns $C$-waa forms), (2) inflectional verbal nouns, (3) base-derived verbal nouns. (1) When no object is expressed, verbs of grades 1, 4, 5, 6 and 7 use a present participial-like stem formed with the suffix '-waa, (i.e. waa preceded by a floating low tone), e.g. tanaa rofeewaa 'she is closing (it)', cf. tanaa rofe taagaa 'she is closing the window'; btiasaa k6omoowaa 'they are not returning', cf. basu k6om6o ba 'they didn't return'; baasaa gyaarowaa 'they are not repairable'. (2) Grades 2 and 3 form verbal nouns by means of a suffix -aa or by vowel length, e.g. Muusaa nee yakee jitaa 'It's Musa who is going out', cf. Muusaa nee ya fita 'It's Musa who went out'. Grade 0 verbs form verbal nouns by vowel length (which operates vacuously if the final vowel is already long) plus low tone, e.g. yanaa soo 'he wants (it)'. Ifthese verbal nouns are followed by an object, they take a connecting linker ( - n or $-F)$ and the 'object' pronoun is represented by a possessive form, e.g. munaa cin naamaa 'we are eating meat', cf mun ci naamaa 'we ate meat'; tanaa tambtiyafsa 'she is asking him', cf. taa tambayee shi 'she asked him'. (3) Many verbs have lexically related verbal nouns that are used instead of or as an optional alternative to verbs or other verbal nouns. Like inflectional verbal nouns, these forms require a linker before expressed objects. The shape of base- 
derived verbal nouns is lexically specific and cannot be predicted from the form of the related verb. The following are some of the more common formation patterns:

(a) -ii H L: ginii 'building'; dlnkii 'sewing'

(b) -ee L H: sayee 'buying'; bincikee 'investigating'

(c) -aa H H: gyaaraa 'repairing'; neemaa 'seeking'

(d) -oo (variable): ciizoo 'biting'; kooy6o 'learning'

(e) Ablaut H L:jiimaa 'tanning' (cf.jeemaa 'tan'); suukila 'piercing' (cf. sookita 'pierce').

Finally, before leaving verbal morphology, two regular deverbal constructions should be mentioned. Adverbs of state are formed from verb stems by means of a suffix -e (with short vowel) and an L $\mathrm{H}$ tone pattern, e.g. zaune 'seated', dafe 'cooked', wafwaatse 'scattered'. Past participial adjectives are formed from verbs by reduplicating the stemfinal consonant in geminate form and adding a suffix -ee (masculine), -iyaa (feminine), with L H H tone, or -uu (plural), with L L H tone, e.g. dafaffee (m.), dafaffiyaa (f.), dafaffeu (pl.) 'cooked', gaagararree, gaagararriyaa, gaagararrou 'obstinate, rebellious'.

\subsubsection{Nominal Morphology}

The major parameters in nominal morphology are gender and number. Hausa has two genders, masculine and feminine, morphologically and grammatically distinguished in the singular only. Masculine words are generally unmarked, ending in consonants and in all five vowels. e.g. teebuf 'table', kiifii 'fish', z6obee 'ring', bilkita 'bow', n6onoo 'breast', tituluu 'pot'. With few exceptions, e.g. mace 'woman', feminine words end in -aa, -(i)yaa or -(u)waa, e.g. kUuraa 'hyena', munduwaa 'anklet', kibiyaa 'arrow', kilazaa 'hen', ta6aryaa 'pestle'. Adjectives are inflected for gender and number, the feminine being formed from the masculine by the addition of - $a$ a (with automatic glide insertion where required), and the plural employing one of the normal nominal formations, e.g. fari $i$ (m.), faraa (f.), faraaree (pl.) 'white'; shUudii, shuudiyaa, shucfdiia 'blue'; d6og6o, d6ogzlwaa, d6ogwaayee 'tall'; saataccee, saatacciyaa, saatattUu 'stolen'.

At the derivational level, many feminine counterparts to masculine humans and animals make use of a suffix -n(i)yaa, e.g. yaaroo, yaarinyaa 'boy, girl'; milkaah0o, makituniyaa 'blind man, woman', birii, birinyaa 'monkey m./f.' Other male/female pairs use the inflectional -aa suffix, e.g.jaakii, jaakita 'donkey m./f.'; kilree, kilryaa 'dog, bitch'.

Nominal plurals represent one of the most complex areas of Hausa morphology. On the surface there are some forty different plural formations making use of infixes, suffixes, reduplication, etc. If, however, one focuses on tone and final vowel, the various plurals can be grouped into a manageable number of basic patterns, see Table 36.6. Although the plural of any given word is not totally predictable, there are correlations and restrictions that hold. For example, almost all singular words that have type (2) plurals have $\mathrm{H} \mathrm{H}$ tone - but not all $\mathrm{H} \mathrm{H}$ singulars have type (2) plurals - whereas type (3) plurals are limited to H L singulars. Within type (2), the variant manifestations of the plural are determined by canonical syllabic structure. Ifthe singular has a light first syllable, it takes a reduplicated plural; if it has an initial open heavy syllable, it takes a glide-containing suffix; if it has an initial closed syllable, it takes an infixing plural. Since there is no one-to-one fit between singulars and plurals, it is not surprising that 
T8ble 3S.e Common Plural Patterns

\begin{tabular}{|c|c|c|c|c|}
\hline & fype & Plural & Singular & Glos1 1 \\
\hline \multirow[t]{3}{*}{ (1) } & ooCii & g1ln6onii & gUriaa & 'melon' \\
\hline & All H & tsar6okii & tsarklyaa & 'bowstring' \\
\hline & & rum8akii & tUmklyaa & 'sheep' \\
\hline \multirow[t]{3}{*}{ (2) } & aа...ee & fagaagee & tagee & 'field' \\
\hline & $\mathrm{H} \mathrm{L} \mathrm{H}$ & z6omaayee & z6om6o & 'hare' \\
\hline & & kas8akee & kask6o & 'bowl' \\
\hline \multirow[t]{3}{*}{ (3) } & aа...aа & sfi'liadaa & sii'dii & 'saddle' \\
\hline & $\mathrm{H} \mathrm{L} \mathrm{H}$ & s8ss3a & s\&ashee & 'section' \\
\hline & & yaaraa & y\&aroo & 'boy' \\
\hline \multirow[t]{6}{*}{ (4) } & uKaa & rligti.nlia & riigaa & 'gown' \\
\hline & H H L & cilainkUrula & cikli & 'belly' \\
\hline & {$[\mathrm{K}=\mathrm{n}, \mathrm{k}, \mathrm{w}$ or Cflnal $]$} & gaarukaa & gaaruu & 'wall' \\
\hline & & y8aziruzUkila & yaajli & 'spice' \\
\hline & & garuuruwaa & gani & 'town' \\
\hline & & c6okU18a & c6okalii & 'spoon' \\
\hline \multirow[t]{3}{*}{ (5) } & $\mathrm{Kii} / \mathrm{Kuu}$ & watannii & wati \a & 'moon, month' \\
\hline & L L H & goon8kii & g6on6a & 'farm' \\
\hline & & raanaikilu & r8anaa & 'sun, day' \\
\hline \multirow[t]{3}{*}{ (6) } & ee...aKii & gareemanii & gili'm8a & 'plough' \\
\hline & H L H H & g6awawwMdi & gaawaa & 'corpse' \\
\hline & & mareemarii & mannaraa & 'laterite' \\
\hline \multirow[t]{3}{*}{ (7) } & ii/uu & bareeyfi & bareewaa & 'gazelle' \\
\hline & L L H & jeemaag<iu & jeemaagee & 'bat' \\
\hline & & mAganganuu & maganaa & 'speech' \\
\hline \multirow[t]{3}{*}{ (8) } & & kUnkUrai & kUnkUn'.l.u & 'tortoise' \\
\hline & L L H & dubbai & dubuu & 'thousand' \\
\hline & & fik8afikai & fiffikee & 'wing' \\
\hline \multirow[t]{8}{*}{ (9) } & Final vowel change & yaatsi'.tu & yaatsaa & 'finger' \\
\hline & & mAasuu & maashii & 'spear' \\
\hline & & 'amaa & 'amee & 'pagan' \\
\hline & & maz.aa & mijii & 'husband, male' \\
\hline & & blr8i & birii & 'monkey' \\
\hline & & cinai & cinyaa & 'thigh' \\
\hline & & k8ajii & k8azaa & 'hen' \\
\hline & & baafii & bilaK6o & 'stranger' \\
\hline
\end{tabular}

many words allow more than one plural, e.g. lee6ee 'lip', pl. /a66aa or /ee6Unda; 6 eefaa 'rat', pl 6eef<layee or 6eefaffakii. An ongoing process in Hausa is the treatment of historically original plurals as singulars, with the subsequent fonnation of new plurals. In some cases the original singular fonn has to be postulated; in others, it still exists as a dialect variant, e.g. dumaa 'gourd' (orig. pl. of dumee), pl. dumaamee; hil.Koorii 'tooth' (orig. pl. of *hairee still found as hiluree), pl. hti.Kooraa; gidaa 'home' (orig. pl. of gijiz), pl. gidaajee.

Hausa has anumber ofproductive and semi-productive nominal derivational constructions, some using prefixes, others using suffixes, some using both.

(a) Ethnonymics, indicating a person's geographical or ethnic origin, social position or, less often, occupation are formed with a prefix ba- in the singular and a 
suppletive suffix -aawaa in the plural, e.g. bahaushee, baha.ushiyaa, hausaawaa 'Ha:VSa man, woman, people'.

(b) Agtials are formed from verbs using a prefix $m a$-, a widespread Afroasiatic fo ative, e.g. manoomii, manoomiyaa, manoomaa 'fanner (m./fJpl.)'.

(c) InstJnllllentals use the same $m a$ - prefix as agentials, but with a different tone patttiern and different plural formation, e.g. mabUudii, mabUudiii 'opener (m./pl.)'.

(d) Loc::ationals use the same $m a$ - prefix, but are usually feminine and end in $-a a$, e.g. ma'ailcataa, ma 'aiktltai 'work-place (f./pl.)'.

(e) Lan age names take a suffix -(n)cii and an all $\mathrm{H}$ tone pattern, e.g. laarabcii 'Ar ic', lcanancii 'Kano dialect' (but not *hausancii, the language name being Musa).

(f) Abs:i:ract nouns make use of an array of related -(n)taa and -(n)cii suffixes with vwying tones, e.g. bautaa 'slavery', gajartaa 'shortness', g-Urgr'lntaa 'lameness', gw< TJiintaa 'expertise', fataucii 'commerce', suusancii 'foolishness'. Another sufix -(n)taktla is sometimes used instead of or in addition to the above, e.g. shee"gO.ntaktla 'rascality', jaaruntaktla =jaaruntaa 'bravery', but mutintaktla 'hUISlan nature' $=f:$. mutuncii 'humaneness, decency'.

(g) Mut11.1ality or reciprocity is indicated by a suffix $-a$.Y,Yaa and/or -eeniyaa, eg. 'aunaata.Y,Yaa 'intermarriage', buga.Y,Yila = bugaggeeniyaa 'hitting one another', yafjeej eeniyaa 'mutual consent'.

\subsection{Syntcax}

\subsubsection{The Noun Phrase}

The key to the Hausa noun phrase is the 'NP-of NP' construction, e.g. ktlalca- $n$ yaaroo 'the boy's !Bfandfather' (lit. 'grandfather-of boy'); m6ota-r-kU 'your car' (lit. 'car-of you (pl.)'); m6ot6oci-n sarlcii 'the chief's cars' (lit. 'cars-of chief'). The 'linker', as it is called by Hausaists, has two forms: $-n$ (a contraction of $n a$ ) and $F$ (a contraction and modificatio:m of ta). The former is used if the first noun is masculine or plural or ends in a vowel othe::r than $-a$; the latter is used if the first noun is feminine singular and ends in $-a$. In all c;ases, the gender of the second nominal is irrelevant. Constructions with the linker have a wide variety of uses, as can be seen from the following typical examples: Mngon cftie:ikii 'wall of the room', gabiln makilrantaa 'in front of the school', diiyarsu 'one of the.m" '.Yaa'.Yan 'itizacee 'fruit' (lit. 'offspring of tree'),jirgin soma 'aeroplane' (lit. 'vehic e of sky'), 'uwaf riigaa 'body (lit. 'mother') of a robe'. The linker also serves to $\mathrm{C}-<$ lnnect a noun and a following demonstrative, e.g.jaalcin nan 'this (here) donkey', 'nkiyar nan 'this (previously referred to) sheep', dawaalcan can 'those horses', anca, as mentioned earlier, to connect verbal nouns with their semantic objects.

There are a number of ways of expressing what in English are translated as adjectival modifiers. One means is to use 'true adjectives' before the modified noun in a linking constructiora, e.g.f.Jrin Zanee 'white clothfara-F riigaa 'whiterobfosassil-n kwalaabee

'broken botltles'. Alternatively (under poorly understood conditions) the adjective can occur to th1ae right of the noun without the use of the linker, e.g. zanee far ii, riigaa faraa ,kwalcrlabeefilsassuu. Attributive cardinal numerals only occur inthis post-nominal position, e..jaaki i diiya 'one donkey', maataa 'ukU 'three women', mayaafDa dubUu 'a thousancll warriors' (cf. dubu-n mayaafDa 'thousands of warriors'). Ordinals also occur to th right of the noun, but make use of a linker (usually non-contracted), e.g. 
liarnii na 'ashirin 'twentieth century', 'alaamaa t4 biyU 'the second sign'. Modifiers are also commonly expressed by use of mailmaasu 'owner, possessor of (sg./pl)' plus an abstract qualitative nominal, e.g. riijiyaa mai zurfii 'a deep well' (cf. zurfinta 'its depth'), leebUroorii maasu Kilrfti 'strong labourers'. This construction has a negative counterpart using marantmarasaa, e.g. rïjiyaa maraf zrirfii 'a not deep well', leebufoon $i$ marasaa liarfii 'not strong labourers'.

Hausa lacks an exact equivalent of the English definite and indefinite articles. The bare noun yaaroo could mean 'a boy' or 'the boy' depending on the context. To specifically indicate that a word has been previously referred to or is the thing in question, there is a suffix identical in segmental shape to the linker but with inherent low tone: '- $n$ (m./pl.), '-r (f.), e.g. yaaron 'the boy in question', runkiyaf 'the sheep in question', mutaanen 'the men referred to'. To indicate particularised indefiniteness, Hausa uses the words wani, wata, wasu (=waoonsu) 'some (m./f./pl.)', e.g. wani ydardo yanaa kUuktia 'a/some boy is crying'; wasu baaKii sunaaj\{rankil 'some strangers are waiting for you'.

\subsubsection{The Sentence}

Hausa has four main sentence types, which can be labelled (a) verbal, (b) tensed nonverbal, (c) existential, and (d) equational.

(a) Verbal sentences have the core structure subject, tense/aspect pronoun, verb, indirect object, direct object or locative goal, instrumental, e.g. yaaroo yanaa gayaa masa laabaarii 'the boy (he) is telling him the news'; mahaukticiyaa taa ktishee shi da wUJiaa 'the crazy woman (she) killed him with a knife', wakiiltii zaasu kOomaa Jiasafsu 'the representatives will return to their countries'. Conditionals, temporals and other complement phrases and clauses occur both before and after the core, e.g. 'in ktia yafda zaamu zaunaa nan sai taa zoo 'if you agree we will sit here until she comes'. In sentences without overt subjects, the tense/aspect pronoun translates as the subject, but syntactically it should not be thought of as such. Thus the sentence yaa hUutaa 'he rested' has the structure 0subj yaa huutaa parallel to the sentence yaaroo yaa hUutaa 'the boy rested'. The TAMs with the segmentally full markers naa, kee and kiln do not require the third person pronominal element if an overt subject is present, e.g. mutaanee (su)naa binsa the men are following him', don mee yaarinyaa (ta)kee kUuktia? 'why is the girl crying?'

The normal position for the indirect object is immediately following the verb and before the direct object. Indirect object pronouns are formed with $m a-$; indirect object nouns make use of a prepositional element $w a$ or $m a$, e.g. t6ocilan taa macee mana 'the flashlight died on us', ktida kQ ktiawoo wa daanaa bindigaa 'don't bring my son a gun'. A long and complex indirect object is likely to be expressed as a prepositional phrase occurring after the direct object. The preposition used in this case is $g a$, etymologically probably the same as wa, eg. naa nuuna takafdaa ga mutUmin da na gamu da shii 'a lioofaa 'I showed the letter to the man I met (lit. 'man that I met with him') at the door'. Compare the normal naa nuunaa wa mutUmin takafdaa 'I showed the man the letter'.

Focused elements are fronted, as is the case with most question words. One consequence (shared with relativisation) is the obligatory substitution of the preterit and relcontinuous for the corresponding completive and continuous TAMs, e.g. mee suka sayaa? 'what did they buy?', cf. sun sayi kiifli 'they bought fish'; waa yakee kidaa? 
'who is drumming?' cf. Muusaa yanaa kidaa 'Musa is drumming'; 'ita cee na gayaa wa 'it was she I told', cf. naa gayaa mata 'I told her'. Another consequence is the use of resumptive pronouns to fill the place of fronted instrumentals and (optionally) indirect objects, e.g. mee zaamu diiure Garaawoo da shii? 'what will we tie up the thief with (it)?'; Hadiza mukee k6oyaa mata (= k6oyaa wa) !Uurancii 'it's Hadiza we're teaching (to her) English'.

(b) Tensed nonverbal sentences make use of the continuous tense/aspect pronouns and a non-verbal predicate, of which there are three major types: locative, 'have' and stative, e.g. munaa nan 'we're here'; Wudi/ baataa mesa da Kanoa 'Wudil is not far from Kano'; sunaa da m6otaa mai kyau 'they have (lit. 'are with') a good car', kwaalin nan yanaa da nauyii 'this carton is heavy' (lit. 'is with heaviness'); 'abinci yanaa dafe 'the food is cooked' (< dafaa 'cook'); !Un jiya sunaa zaune 'a f(6ofar gidankii 'since yesterday they have been sitting at the door of your house' (< zaunaa 'sit'); munaa sane da shii 'we are aware of it' (< sanii 'know'). As in the case of verbal sentences, fronting of a questioned or focused element in these sentence types triggers the use of rel-continuous tense/aspect pronouns, e.g. 'inaa suke yanzu? 'where are they now?'; mee kake da shii? 'what do you have?' (lit. 'what are you with it'); muluu 'a cike yake 'the pot is filled' (lit. 'the pot filled it is'). (Note that the form of the rel-continuous differs slightly here in having a short final vowel.)

As a general rule, Hausa is a language with fairly fixed word order. Changes from normal order occur for specific grammatical or pragmatic purposes such as when questioned or focused elements are fronted. Hausa does not deviate from normal word order in yes-no questions. These are indicated simply by a question tag (such as $k 60$ 'or' or $f a$ 'what about?') or by question intonation (consisting in part of an old question morpheme now reflected only as vowel length often with low tone), e.g. Muusaa zdi yarda k6o? 'Musa will agree, right?'; baaKii sunfitaa? 'did the guests go out?' (jitda= fita + ':), cf. baaKii sun fita 'the guests went out'.

(c) Existential sentences, which are high frequency in the language, are formed with the word 'akwai 'there is/there are' and the negative counterpart biia (or baabu) 'there's not', e.g. 'akwai 'abinci mai daadii 'there is delicious food'; baa 'isasshen $k U$ dii 'there is not enough money'.

(d) Equational sentences have the structure (NP) NP neelcee (with polar tone), where nee has masculine and plural agreement and cee $(<*$ tee) has feminine agreement, e.g. shii s6oja nee 'he is a soldier', m6otar nan saabUwaa cee 'this car is new'. These sentences are negated by sandwiching the second noun phrase between baa ... ba, e.g. shii baa s6oja $\mathrm{M}$ nee 'he is not a soldier', m6otaf nan baa saabUwaa $\mathrm{M}$ cee 'this car is not new'. If the first noun phrase is missing, one has an identificational sentence comparable to English 'it's a ...', e.g. kiiree nee 'it's a dog'; baa taawa $\mathbf{M}$ cee 'it's not mine'. Equational sentences are not marked for tense; thus the preceding sentence could equally mean 'it wasn't mine'.

\section{Bibliography}

Newman (1977), which builds on Newman and Ma (1966), is the standard work on Chadic classification and on the reconstruction of Proto-Chadic, whereas Newman (1980) provides the basis for the membership of Chadic within the Afroasiatic phylum. 'Three solid reference grammars of Hausa are Wolff (1993), Newman (2000) and Jaggar (2001). The classic grammar of Abraham (1959), which 
dates back to 1940, is still worth consulting. Parsons (1981) is an invaluable collection of papers and lecture notes by the leading Hausaist of his time. A translation of K.lingenheben's Law with commentary is provided in Newman (2004). Abraham (1962) and Bargery (1934) are outstanding comprehensive Hausa-English dictionaries. The English-Hausa dictionary of R.M. Newman (1990) contains a wealth of illustrative examples, all accurately marked for tone and vowel length. A Hausa-English counterpart to this dictionary is now available (Newman 2007). A convenient pocket dictionary is Awde (1996). For a fully comprehensive bibliography of works on Charlie and Hausa up to the time of its publication, see Newman (1996).

\section{References}

Abraham, R.C. 1959. The language of the Hausa People (University of London Press, London)

— 1962.Dictionary \& the Hausa language, 2ndedn(University of London Press, London)

Awde, N. 1996.Hausa-English English-Hausa Dictionary (Hippocrene Books, New York)

Bargery, G.P. 1934. A Hausa-English Dictionary and English-Hausa Vocabulary (Oxford University

Press, London; reprint with supplement and new introduction by A.N. Skinner, Ahmadu Bello University Press, Zaria, 1993)

Jagger, PJ. 2001. Hausa. London Oriental and African Language Library,7 (John Benjamins, Amsterdam)

Newman, P. 1977. Chadic Classification and Reconstructions (Undena, Malibu, Calif.)

- 1980. The Classification of Chadic within Afroasiatic (Universitaire Pers, Leiden)

- - 1996. Hausa and the Chadic language Family: A Bibliography (African Linguistic Bibliographies, 6). (Rudiger Koppe Verlag, Cologne)

-2000. The Hausa Language: An Encyclopedic Reference Grammar (Yale University Press, New Haven)

- -2004. Klingenheben $S$ Law in Hausa. Charlie Linguistics, 2 (Rudiger Koppe Verlag, Cologne) -2007. A Hausa-English Dictionary (Yale University Press, New Haven)

Newman, P. and Ma, R. 1966. 'Comparative Charlie: Phonology and Lexicon', Journal of African languages, vol. 5, pp. 218-51.

Newman, R.M. 1990. An English-Hausa Dictionary (Yale University Press, New Haven)

Parsons, F.W. 1981. Writings on Hausa Grammar, ed. G. Furniss, 2 vols (School of Oriental and African Studies, London)

Wolff, Ekkehard. 1993. Referenzgrammatik des Hausa. Hamburger Beitrlige zur Afrikanistik, 2 (Lit, Miinster and Hamburg) 